\title{
Psychiatrists' attitudes, knowledge, and experience regarding genetics: a preliminary study
}

Jinger G. Hoop, $M D, M F A^{1}$, Laura Weiss Roberts, $M D, M A^{1,2}$, Katherine A. Green Hammond, $P h D^{3}$, and Nancy J. Cox, $P h D^{4}$

\begin{abstract}
Purpose: This study is the first survey of a random national sample of US psychiatrists to assess attitudes, knowledge, and clinical experience regarding genetics. We hypothesized that clinicians with more recent genetics training would demonstrate more positive attitudes and greater genetics knowledge and experience than those with less recent training. Methods: A probability sample of US psychiatrists $(n=93)$ was invited to participate in a mail survey regarding genetic medicine. Results: Forty-five psychiatrists completed the survey (response rate $=48 \%$ ). All believed that genetics strongly or moderately influenced a person's mental health. Respondents expressed positive attitudes toward incorporating genetics into psychiatric practice, but most did not have recent genetics training or experience in referring patients to genetic counselors or ordering genetic tests. Psychiatrists who had genetics training within the previous 5 years had more experience in providing genetic services. Conclusions: This survey identified areas of strength (positive attitudes about providing genetic services, belief in the heritability of mental illness) and future targets for educational intervention (general genetics, information about testing and counseling resources). The association between recent training and a greater level of clinical genetics experience suggests that educational efforts may be successful in preparing psychiatrists to provide genetic services in the future. Genet Med 2008:10(6):439-449.
\end{abstract}

Key Words: genetics, psychiatry, survey, attitudes, medical education

Mental illnesses are among the most disabling conditions of humankind, causing the suffering of hundreds of millions of patients and families across the world. Psychiatric genetic research represents a bright hope for reducing this suffering by improving scientific understanding of the pathophysiology of mental disorders, creating new opportunities for rationally based treatments. ${ }^{1-6}$ In addition, empirical data suggest that people living with mental illness and their families are eager for genetic research findings to be quickly translated into clinical genetic services. Surveys of these stakeholders have consistently demonstrated high levels of interest in genetic counseling and genetic testing for variants associated with mental illness. ${ }^{7-14}$ Genetic tests are currently available for certain rare highly penetrant disorders with psychiatric manifestations, and recurrence risks can be estimated for persons with a family history of common mental illnesses such as schizophrenia, major depression, and bipolar disorder. As research findings of

From the ${ }^{1}$ Department of Psychiatry and Behavioral Medicine, and the ${ }^{2}$ Health Policy Institute, Medical College of Wisconsin, Milwaukee; ${ }^{3}$ Consultant in Statistics and Population Modeling, Ecosystem Modeling, Albuquerque, New Mexico; and ${ }^{4}$ Section of Genetic Medicine, Department of Internal Medicine, University of Chicago, Chicago, Illinois.

Jinger G. Hoop, MD, MFA, 8701 Watertown Plank Road, Milwaukee, WI 53226. E-mail: jhoop@mcw.edu

Disclosure: The authors declare no conflict of interest.

Submitted for publication October 26, 2007.

Accepted for publication January 30, 2008.

DOI: $10.1097 /$ GIM.0b013e318177014b susceptibility variants for common mental illnesses have begun to be replicated in independent samples, ${ }^{6}$ it has become increasingly important to consider whether and how these discoveries should be translated into patient care. ${ }^{15-17}$

Genetic counselors and medical geneticists have traditionally been the health care providers who bring genetic research advances to the clinic, but the number of these professionals is predicted to be too small to handle the future demand for services from the many millions of people at risk for complex inheritance disorders such as common mental illnesses. ${ }^{18}$ It is therefore expected that psychiatrists increasingly will be called upon to provide genetic counseling and testing to patients and their family members. ${ }^{15-17}$ This will be an almost entirely new role for psychiatrists, who typically receive little or no instruction in clinical genetics during their postgraduate training. ${ }^{15}$

As of 2008, there had been few systematic attempts to learn whether psychiatrists are willing to take on this role, and if so, whether they have the necessary education and experience to do so. Among the existing psychiatrist surveys on the topic of genetic medicine, ${ }^{7,10,19-22}$ many have assessed psychiatrists' knowledge of genetics through exam-style questions, and they have found it to be poor. Because these studies have typically used convenience or other nonprobability samples, whether their findings are generalizable is unknown. To our knowledge, no recent assessment of psychiatrists' preparedness to offer 
genetic counseling and testing has been undertaken using sampling techniques with the potential for generalizability.

The current preliminary study was created to address this gap in our knowledge by polling a random national sample of psychiatrists regarding their genetics education, attitudes toward providing genetic services, knowledge of clinical genetics resources and of the heritability of conditions and traits, and experience in providing three types of genetic services: genetic counseling to patients and families, referrals to genetic counselors, and genetic testing. We hypothesized that more recent genetics training would be associated with a greater preparedness to provide genetic services.

\section{MATERIALS AND METHODS}

This observational study was a self-administered survey mailed to a probability sample of US psychiatrists in 2006. The survey protocol conforms to institutional requirements for human-subjects research, and was approved by the University of Chicago Social Sciences Division institutional review board.

\section{Sample}

The sample consisted of 100 psychiatrists whose names and addresses were randomly drawn from the American Medical Association (AMA) masterfile. The AMA masterfile contains demographic data on almost every physician practicing in the United States (not limited to AMA members) and is considered a comprehensive and unbiased source. ${ }^{23}$ All MDs and more than $93 \%$ of DOs practicing in the United States are included. ${ }^{24}$ Data in the AMA masterfile are compiled, updated, and verified through weekly surveys of medical schools, residency training institutions, state licensing agencies, the US Drug Enforcement Agency, the National Board of Medical Examiners, and other regulatory bodies. ${ }^{25}$

To increase response rates to the survey, up to three questionnaires were mailed to each potential respondent at 3- to 4-week intervals. The third mailing included a 2-dollar bill as a token compensation. Of the 100 surveys mailed, seven were returned as undeliverable or because the physician had retired from practice. Of the remaining 93 potential respondents, 45 completed and returned the questionnaire, yielding a response rate of $48 \%$. There were no significant differences between respondents and nonrespondents for all demographic variables that could be assessed (Table 1). In both groups 29\% were women $(P<0.96)$. Respondents' mean age was $52(\mathrm{SD}=11)$ and nonrespondents' was $54(\mathrm{SD}=13)(P<0.46)$. Sixty-nine percent of the respondents and $63 \%$ of the nonrespondents were board certified $(P<0.52)$. Seventy-one percent of respondents and $73 \%$ of nonrespondents were graduates of US medical schools $(P<0.85)$.

\section{Measures}

The survey instrument was a 94-item self-administered questionnaire consisting of questions regarding genetic medicine. Here, we report the survey items concerning psychiatrists' preparedness to provide genetic services. For the pur-
Table 1

Characteristics of psychiatrist respondents $(N=45)$ and nonrespondents $(N=48)$

\begin{tabular}{|c|c|c|c|c|}
\hline & \multicolumn{2}{|c|}{ Respondents } & \multicolumn{2}{|c|}{ Nonrespondent } \\
\hline & $f$ & $\%$ & $f$ & $\%$ \\
\hline \multicolumn{5}{|l|}{ Gender } \\
\hline Women & 13 & 29 & 14 & 29 \\
\hline Men & 32 & 71 & 34 & 71 \\
\hline Mean age in years (SD) & 52 & $(11)$ & 54 & $(13)$ \\
\hline Board certified & 31 & 69 & 30 & 63 \\
\hline \multicolumn{5}{|l|}{ Location of medical training } \\
\hline United States & 32 & 71 & 35 & 73 \\
\hline Foreign & 13 & 29 & 13 & 27 \\
\hline \multicolumn{5}{|l|}{ Ethnicity } \\
\hline White, not Hispanic & 30 & 67 & & \\
\hline Asian & 5 & 11 & & \\
\hline Hispanic & 2 & 4 & & \\
\hline Not reported & 8 & 18 & & \\
\hline \multicolumn{5}{|l|}{$\begin{array}{c}\text { How do you spend the majority } \\
\text { of your professional time? }\end{array}$} \\
\hline $\begin{array}{l}\text { Outpatient } \\
\text { psychopharmacology }\end{array}$ & 26 & 58 & & \\
\hline $\begin{array}{l}\text { Hospital or inpatient } \\
\text { psychiatry }\end{array}$ & 6 & 13 & & \\
\hline Other or multiple responses & 13 & 29 & & \\
\hline \multicolumn{5}{|l|}{$\begin{array}{l}\text { Have you had any of the } \\
\text { following types of } \\
\text { education in genetics? }\end{array}$} \\
\hline Undergraduate course & 31 & 69 & & \\
\hline Graduate genetics course & 15 & 33 & & \\
\hline Medical school course & 37 & 82 & & \\
\hline Residency course & 11 & 24 & & \\
\hline Fellowship course & 4 & 9 & & \\
\hline CME course & 20 & 44 & & \\
\hline Grand rounds & 27 & 60 & & \\
\hline \multicolumn{5}{|l|}{$\begin{array}{l}\text { How long ago was your most } \\
\text { recent training in genetics? }\end{array}$} \\
\hline Within the last 2 yrs & 10 & 22 & & \\
\hline $3-5$ yrs ago & 8 & 18 & & \\
\hline $6-10$ yrs ago & 6 & 13 & & \\
\hline $11-20$ yrs ago & 5 & 11 & & \\
\hline More than 20 yrs ago & 11 & 24 & & \\
\hline No genetics training & 5 & 11 & & \\
\hline
\end{tabular}

poses of this survey, physician "preparedness" includes the following domains: educational background, attitudes toward becoming a provider of genetic services; knowledge of the heritability of disorders and traits and of clinical genetics resources; 
and experience with providing clinical genetics services, including family-history taking, genetic counseling, and genetic testing. Survey questions and response choices are reproduced verbatim in Tables 1-6. Survey responses regarding the future use of genetic testing in psychiatry and appropriate patient safeguards have been reported elsewhere. ${ }^{26}$

The instrument was based in part on previously administered questionnaires, ${ }^{21,27}$ but was modified to exclude questions that directly tested respondents' factual knowledge about genetics. These questions were presumed to increase the cognitive burden of the survey and to potentially increase the nonresponse rate, particularly among clinicians with less knowledge of genetics. The survey was pretested with clinical psychiatrists and critically reviewed by experts in psychiatric genetics and experts in survey design at the University of Chicago. All mailings included a cover letter explaining that the survey was not a test of the participant's genetic knowledge and requesting participation by all clinicians, including those with little or no background or interest in genetics.

\section{Data analysis}

Categorical response frequencies are reported. Small differences in sample size arise from sporadic missing responses. Separate analyses were conducted with gender, age, board certification, and aspects of training as between-subject variables, and only the analysis using the timing of genetics training yielded any consistent or meaningful pattern of results. This variable was defined by respondents' answers to the survey question, "How long ago was your most recent training in genetics?" Conceptually related sets of rating scaled responses were subjected to within-subjects repeated measures multivariate analysis of variance. Differences in response patterns between subjects with and without recent training in genetics (genetics training within the last 5 years versus training more than 5 years ago or no training) were compared using $\chi^{2}$ or Fisher exact tests.

\section{RESULTS}

\section{Participant characteristics}

Our 45 psychiatrist respondents were 29\% women and $71 \%$ men. Ages ranged from 30 to 74 years, with mean age 52 years $(\mathrm{SD}=11)$. Sixty-nine percent were board certified, $44 \%$ held an academic appointment (defined broadly to include adjunct appointments), and $71 \%$ were graduates of US medical schools. Women were younger than men (respective means $=$ 44 vs. $56, P<0.01$ ) and less likely to be board certified ( $46 \%$ vs. $78 \%, P<0.04)$. Thirty-six percent of responding psychiatrists treated children or adolescents routinely (Table 1).

\section{Genetics education and training}

Sixty-nine percent of respondents had taken an undergraduate genetics course, and 33\% had taken a graduate course. Most (82\%) had a genetics course in medical school, $24 \%$ had a course in residency, and $9 \%$ had a course in fellowship. Nearly half of respondents (44\%) had attended a continuing medical education (CME) course in genetics, and 60\% had attended a grand rounds lecture on the topic. Forty percent of psychiatrists reported that they had some type of training in genetics within the previous 5 years, $22 \%$ of them within the last 2 years, and $18 \%$ from 3 to 5 years ago. Of the remainder of the sample, $13 \%$ had training in genetics from 6 to 10 years ago, $11 \%$ from 11 to 20 years ago, $24 \%$ from more than 20 years ago, and $11 \%$ said they had not had genetics training. Those with genetics training within the past 5 years were significantly younger than the other respondents (mean age $=48$ vs. $55, P<$ $0.04)$, but the groups did not differ in gender composition, ethnicity, training location, board certification status, holding an academic appointment, or treating children or adolescents (Table 1).

\section{Perceptions of the influence of genetics on disorders, traits, and abilities}

Psychiatrist respondents rated the influence of genetics (scaled from $1=$ "none" to $2=$ "weak" to $3=$ "moderate" to $4=$ "strong") on general mental health and on 10 psychiatric disorders; 8 traits, behaviors, and abilities; and 9 medical disorders. All respondents indicated that genetics or heredity has a strong or moderate influence on a person's overall mental health $(64 \%$ and $36 \%$ of responses, respectively) (mean $=$ 3.64; $\mathrm{SD}=0.48)$. Participants believed that genetics has a strong influence on Huntington disease (mean $=3.90)$, moderately strong influence on alcoholism, bipolar disorder, schizophrenia, Alzheimer disease, attention-deficit hyperactivity disorder, and major depressive disorder (means $=3.24$ 3.54), and moderate influence on panic disorder, autism, and antisocial personality disorder ( means $=2.62-2.86$; Item main effect $F(9,35)=15.34, P<0.0001$, maximum Cohen $d=2.0)$ (Table 2).

In answers to questions about traits, behaviors, and abilities, respondents indicated that genetics has moderate influence on cognitive ability, athletic ability, and creativity (means $=2.95$ 3.22) and a weak to moderate influence on extroversion, aggressive behavior, risk-taking behavior, neuroticism, and conscientiousness (means $=2.40-2.75$; Item main effect $F(7,38)=$ $7.74, P<0.0001$, maximum $d=1.19$ ). When asked about the influence of genetics on medical disorders, respondents indicated that genetics has moderate influence on which individuals develop cardiovascular disease, breast cancer, colon cancer, obesity, type II (noninsulin dependent) diabetes, asthma, and inflammatory bowel disease (means $=2.92-3.40)$ and weak to moderate influence on which individuals develop multiple sclerosis or lung cancer (means $=2.40-2.65$; Item main effect $F(8,36)=8.60, P<0.0001$, maximum $d=1.45)$.

Respondents indicated that genetics has moderate influence on the set of psychiatric disorders (excluding Huntington disease to avoid skewing the results because it was the only condition listed with solely Mendelian inheritance) and on the set of medical disorders (means $=3.02-3.19$ ) and smaller but still moderate influence on traits, behaviors, and abilities (mean = 2.79; Item main effect $F(2,42)=16.45, P<0.0001$, maximum $d=0.89)$. 
Table 2

Psychiatrists' estimates of the influence of genetics on disorders, behaviors, traits, and abilities

\begin{tabular}{|c|c|c|c|c|c|}
\hline \multirow[b]{2}{*}{ Item } & \multicolumn{4}{|c|}{ Influence of genetics ( $\%$ of responses) } & \multirow{2}{*}{$\begin{array}{l}\text { Overall rating }^{a} \\
\text { Mean }(\mathrm{SD})\end{array}$} \\
\hline & None & Weak & Moderate & Strong & \\
\hline \multicolumn{6}{|c|}{$\begin{array}{l}\text { How much influence does genetics or heredity have on a } \\
\text { person's mental health? }\end{array}$} \\
\hline \multicolumn{6}{|c|}{$\begin{array}{l}\text { How much does genetics influence which individuals develop } \\
\text { the following psychiatric disorders? }(N=44)^{b}\end{array}$} \\
\hline Huntington disease & - & - & 9 & 91 & $3.90(0.28)$ \\
\hline Alcoholism & - & 2 & 41 & 57 & $3.54(0.53)$ \\
\hline Bipolar disorder & - & 5 & 36 & 59 & $3.53(0.54)$ \\
\hline Schizophrenia & - & 7 & 49 & 44 & $3.37(0.56)$ \\
\hline Alzheimer disease & - & 7 & 56 & 38 & $3.30(0.52)$ \\
\hline Attention-deficit hyperactivity disorder & - & 13 & 47 & 40 & $3.28(0.61)$ \\
\hline Major depressive disorder & - & 11 & 53 & 36 & $3.24(0.61)$ \\
\hline Panic disorder & 2 & 20 & 67 & 11 & $2.86(0.62)$ \\
\hline Autism & 2 & 36 & 36 & 27 & $2.86(0.51)$ \\
\hline Antisocial personality disorder & 4 & 44 & 36 & 16 & $2.62(0.74)$ \\
\hline \multicolumn{6}{|c|}{$\begin{array}{l}\text { How much does genetics influence the following traits, } \\
\text { behaviors, or abilities? }(N=45)^{c}\end{array}$} \\
\hline Cognitive ability & - & 11 & 56 & 33 & $3.22(0.64)$ \\
\hline Athletic ability & - & 18 & 58 & 24 & $3.07(0.66)$ \\
\hline Creativity & 2 & 20 & 58 & 20 & $2.95(0.68)$ \\
\hline Extroversion & 4 & 24 & 62 & 9 & $2.75(0.67)$ \\
\hline Aggressive behavior & 2 & 38 & 49 & 11 & $2.68(0.60)$ \\
\hline Risk-taking behavior & 7 & 27 & 60 & 7 & $2.66(0.70)$ \\
\hline Neuroticism & 7 & 31 & 56 & 7 & $2.62(0.71)$ \\
\hline Conscientiousness & 13 & 36 & 49 & 2 & $2.40(0.75)$ \\
\hline \multicolumn{6}{|c|}{$\begin{array}{l}\text { How much does genetics influence which individuals develop } \\
\text { the following medical disorders? }(N=44)^{d}\end{array}$} \\
\hline Cardiovascular disease & - & 4 & 51 & 44 & $3.40(0.57)$ \\
\hline Breast cancer & - & 11 & 44 & 44 & $3.33(0.66)$ \\
\hline Colon cancer & - & 9 & 51 & 40 & $3.31(0.63)$ \\
\hline Obesity & 4 & 4 & 60 & 31 & $3.18(0.73)$ \\
\hline Type II (noninsulin dependent) diabetes & 2 & 16 & 64 & 18 & $2.98(0.67)$ \\
\hline Asthma & 2 & 20 & 60 & 18 & $2.93(0.70)$ \\
\hline Inflammatory bowel disease & 2 & 20 & 60 & 18 & $2.92(0.65)$ \\
\hline Multiple sclerosis & 7 & 36 & 44 & 13 & $2.65(0.77)$ \\
\hline Lung cancer & 7 & 49 & 40 & 4 & $\begin{array}{l}2.40(0.63) \\
(\text { Continued })\end{array}$ \\
\hline
\end{tabular}

\section{Attitudes and experiences regarding genetic counseling}

About three-quarters of respondents (78\%) considered psychiatrists to be the most appropriate professional to counsel psychiatric patients about the role of genetics in their disease, $13 \%$ identified a genetic counselor as the most appropriate provider, and $7 \%$ selected a medical geneticist for this role.
None considered counseling to be unnecessary. Almost all psychiatrists (95\%) believed it was their role to discuss genetic information regarding psychiatric illness with patients and their families (Table 3). A majority (70\%) of psychiatrists stated that they felt competent to do this, and $60 \%$ believed that their medical training had prepared them for the task. 
Table 2

Continued

\begin{tabular}{llllll}
\hline & & \multicolumn{3}{c}{ Influence of genetics (\% of responses) } & \multicolumn{2}{c}{ Overall rating ${ }^{a}$} \\
\cline { 2 - 4 } Item & None & Weak & Moderate & Strong & Mean (SD) \\
\hline
\end{tabular}

Calculated means for the perceived influence of genetics

upon the following: $(N=44)^{e}$

Psychiatric disorders ${ }^{f}$

$3.19(0.44)$

Traits, behaviors, and abilities ${ }^{g}$

$2.79(0.48)$

Medical disorders ${ }^{h}$

$3.02(0.45)$

"Scaled from 1 = "no influence" to 2 = "weak influence" to $3=$ "moderate influence" to 4 = "strong influence."

${ }^{b}$ Overall rating from an item (within subjects) repeated measures MANOVA. Item $P<0.0001$; pooled $\mathrm{SD}=0.64$. Differences in overall means $>0.24$ differ at $P<$ 0.05 by Fisher LSD.

${ }^{c}$ Overall rating from an item (within subjects) repeated measures MANOVA. Item $P<0.0001$; pooled $\mathrm{SD}=0.69$. Differences in overall means $>0.24$ differ at $P<$ 0.05 by Fisher LSD.

${ }^{d}$ Overall rating from an item (within subjects) repeated measures MANOVA. Item $P<0.0001$; pooled $\mathrm{SD}=0.69$. Differences in overall means $>0.28$ differ at $P<$ 0.05 by Fisher LSD.

${ }^{e}$ Overall rating from an item (within subjects) repeated measures MANOVA. Item $P<0.0001$; pooled $\mathrm{SD}=0.45$. Differences in overall means $>0.15$ are significant at $P<0.05$ by Fisher LSD.

${ }^{f}$ Mean across all psychiatric disorders above except Huntington disorder (alcoholism, Alzheimer disease, antisocial personality disorder, attention-deficit hyperactivity disorder, autism, bipolar disorder, major depressive disorder, panic disorder, and schizophrenia).

${ }^{8}$ Mean across all behaviors and abilities above (aggressive behavior, athletic ability, cognitive ability, conscientiousness, creativity, extroversion, risk-taking behavior, and neuroticism).

${ }^{h}$ Mean across all medical disorders above (asthma, breast cancer, cardiovascular disease, colon cancer, inflammatory bowel disease, lung cancer, multiple sclerosis, obesity, and type II [noninsulin dependent] diabetes).

Table 3

Psychiatrists' attitudes toward providing genetic services ${ }^{a}$

\begin{tabular}{|c|c|c|}
\hline & $f$ & $\%$ \\
\hline \multicolumn{3}{|c|}{$\begin{array}{l}\text { You feel that it is your role to discuss genetic information } \\
\text { regarding psychiatric illness with patients and their } \\
\text { families }(N=44)\end{array}$} \\
\hline Agree & 42 & 95 \\
\hline Disagree & 2 & 5 \\
\hline \multicolumn{3}{|c|}{$\begin{array}{l}\text { You feel competent to discuss genetic information } \\
\text { regarding psychiatric illness with patients and their } \\
\text { families }(N=44)\end{array}$} \\
\hline Agree & 31 & 70 \\
\hline Disagree & 13 & 30 \\
\hline \multicolumn{3}{|c|}{$\begin{array}{l}\text { Your medical training has prepared you to discuss } \\
\text { genetic information regarding psychiatric illness } \\
\text { with patients and their families }(N=43)\end{array}$} \\
\hline Agree & 26 & 60 \\
\hline Disagree & 17 & 40 \\
\hline \multicolumn{3}{|c|}{$\begin{array}{l}\text { You feel competent to offer genetic tests for psychiatric } \\
\text { illness and interpret the results }(N=43)\end{array}$} \\
\hline Agree & 4 & 9 \\
\hline Disagree & 39 & 91 \\
\hline
\end{tabular}

${ }^{a}$ Variation in reported $N$ is due to missing or incomplete responses.

Eighty-six percent of respondents reported that they routinely take detailed family histories of psychiatric illness during the evaluation of patients (Table 4). More respondents with training in genetics within the previous 5 years said that they routinely take family histories compared with those without such recent training $(100 \%$ vs. $77 \%, P<0.07$, Fisher exact test). More respondents with recent training in genetics than without it reported discussing the genetic component of psychiatric illness with all or most of their patients ( $89 \%$ vs. $64 \%$, $P<0.09$, Fisher exact test). A minority (23\%) of psychiatrist respondents reported that telling a patient that there is a genetic component to his or her illness tends to make the patient less distressed about having a psychiatric illness; 5\% reported that patients tend to be more distressed; and 53\% reported that reactions vary among patients.

Psychiatrists were asked to indicate which of seven clinical scenarios represented situations in which they would provide genetic counseling themselves and in which they would refer patients to a genetic counselor, assuming that a trusted colleague who could provide affordable counseling was available (Table 5). Most respondents $(72 \%$ and $70 \%$, respectively) would personally counsel an individual with a family history of mental illness who wondered about his or her own risk of developing the disorder or a patient who wondered about the risk of passing on mental illness to his or her child. Half (50\%) of respondents would refer to a genetic counselor in the case of a family with multiple family members affected with the same mental illness. Most (59$84 \%$ ) would refer for genetic counseling a couple with a family history of mental illness and family planning questions, a patient with mental illness and mental retardation, or a patient with mental illness and multiple congenital anomalies. Significantly more respondents would refer to a genetic counselor in the last case than in the other six $(84 \%$ vs. $21-61 \%$, all $P<0.03$, Fisher exact test), and significantly fewer respondents would refer to a genetic counselor in the first three cases than in the others ( $21-30 \%$ vs. $50-84 \%$, all $P<0.09$, Fisher exact test). 
Table 4

Psychiatrists' personal experience in counseling patients about genetics

\begin{tabular}{|c|c|c|c|c|c|c|}
\hline & \multicolumn{4}{|c|}{ Trained in genetics within the previous $5 \mathrm{yrs}$} & \multicolumn{2}{|c|}{ Overall } \\
\hline & \multicolumn{2}{|c|}{ Yes } & \multicolumn{2}{|c|}{ No } & \multirow[b]{2}{*}{$f$} & \multirow[b]{2}{*}{$\%$} \\
\hline & $f$ & $\%$ & $f$ & $\%$ & & \\
\hline \multicolumn{7}{|l|}{$\begin{array}{l}\text { Do you routinely take detailed family histories of psychiatric illness } \\
\text { during the evaluation of your patients? }(N=44)^{a}\end{array}$} \\
\hline Yes & 18 & 100 & 20 & 77 & 38 & 86 \\
\hline No & 0 & 0 & 6 & 23 & 6 & 14 \\
\hline \multicolumn{7}{|l|}{$\begin{array}{l}\text { How often do you discuss with patients the extent to which there is a } \\
\text { genetic or hereditary component to the patient's psychiatric } \\
\text { illness? }(N=43)^{b}\end{array}$} \\
\hline With all of my patients & 7 & 39 & 4 & 16 & 11 & 26 \\
\hline With most of my patients & 9 & 50 & 12 & 48 & 21 & 49 \\
\hline With some of my patients & 2 & 11 & 7 & 28 & 9 & 21 \\
\hline With none of my patients & 0 & 0 & 2 & 8 & 2 & 5 \\
\hline \multicolumn{7}{|l|}{$\begin{array}{l}\text { When you tell a patient that there is a genetic component to his or her } \\
\text { illness, would you say this tends to make the patient: }(N=43)\end{array}$} \\
\hline More distressed about having a psychiatric illness & & & & & 2 & 5 \\
\hline Less distressed about having a psychiatric illness & & & & & 10 & 23 \\
\hline Neither more nor less distressed about having a psychiatric illness & & & & & 8 & 19 \\
\hline Varies among patients—-have seen both reactions about equally & & & & & 23 & 53 \\
\hline
\end{tabular}

${ }^{a}$ Proportions differ by recency of training, $P<0.07$, by Fisher exact test.

${ }^{b}$ Proportions for with all or most patients vs. with some or none differ by recency of training, $P<0.09$, by Fisher exact test.

Table 5

Psychiatrists' preferences regarding genetic counseling

\begin{tabular}{|c|c|c|c|c|c|}
\hline & \multicolumn{2}{|c|}{$\begin{array}{l}\text { Address this } \\
\text { yourself }\end{array}$} & \multicolumn{2}{|c|}{$\begin{array}{l}\text { Refer to a genetic } \\
\text { counselor }\end{array}$} & \multirow[b]{2}{*}{$N$} \\
\hline & $f$ & $\%$ & $f$ & $\%$ & \\
\hline \multicolumn{6}{|l|}{$\begin{array}{l}\text { If you had a trusted colleague who could provide affordable genetic counseling to your } \\
\text { patients, in which of the following situations would you refer to the colleague and } \\
\text { in which would you address the issue yourself? }\end{array}$} \\
\hline A woman with questions about the safety of medication use during pregnancy & 34 & 79 & 9 & 21 & 43 \\
\hline $\begin{array}{l}\text { A person with a family history of mental illness who wonders about his/her own risk } \\
\text { of developing the disorder }\end{array}$ & 31 & 72 & 12 & 28 & 43 \\
\hline A patient who wonders about the risk of passing on mental illness to his or her child & 30 & 70 & 13 & 30 & 43 \\
\hline A family with multiple family members affected with the same mental illness ${ }^{a}$ & 22 & 50 & 22 & 50 & 44 \\
\hline A couple with a family history of mental illness and family planning questions & 18 & 41 & 26 & 59 & 44 \\
\hline A patient with mental illness and mental retardation & 17 & 39 & 27 & 61 & 44 \\
\hline A patient with mental illness and multiple congenital anomalies ${ }^{b}$ & 7 & 16 & 36 & 84 & 43 \\
\hline
\end{tabular}

${ }^{a}$ Response proportions differ from those of the items above, all $P<0.09$, Fisher exact test.

${ }^{b}$ Response proportions differ from those of the items above, all $P<0.03$, Fisher exact test.

The majority $(88 \%)$ of psychiatrists, however, had not referred any patients for consultation regarding a genetic component of psychiatric illness during the past year (Table 6). Only $13 \%$ of respondents were aware of any professional, such as a medical geneticist or genetic counselor, providing genetic counseling to psychiatric patients in the geographic area where they practice. More than three-quarters of respondents (82\%) did not know whether most forms of insurance in their geographic area covered genetic counseling.

\section{Attitudes and experience regarding genetic testing}

Only $9 \%$ of respondents said they felt competent to offer genetic tests for psychiatric illness and to interpret the results (Table 3). Twenty-four percent of those who had been trained 
Table 6

Psychiatrists' experience and knowledge regarding genetic counseling referrals and genetic testing ${ }^{a}$

\begin{tabular}{|c|c|c|}
\hline & $f$ & $\%$ \\
\hline \multicolumn{3}{|c|}{$\begin{array}{l}\text { Over the past year, how many patients have you } \\
\text { referred for consultation regarding a } \\
\text { genetic component of psychiatric illness in } \\
\text { themselves or family members? }(N=43)\end{array}$} \\
\hline No patients & 38 & 88 \\
\hline One or two patients & 5 & 12 \\
\hline Three or more patients & 0 & - \\
\hline \multicolumn{3}{|c|}{$\begin{array}{l}\text { During the past } 5 \text { yrs, have you ordered a } \\
\text { genetic test for: (responses of yes from } \\
N=42 \text { ) }\end{array}$} \\
\hline Fragile X syndrome & 6 & 14 \\
\hline Huntington disease & 4 & 10 \\
\hline Alzheimer disease & 2 & 5 \\
\hline Neurofibromatosis & 1 & 2 \\
\hline Velocardiofacial syndrome & 0 & - \\
\hline Any other genetic test & 2 & 5 \\
\hline No tests ordered & 33 & 79 \\
\hline \multicolumn{3}{|c|}{$\begin{array}{l}\text { Are you aware of any professional, such as a } \\
\text { medical geneticist or genetic counselor, } \\
\text { who provides genetic counseling to } \\
\text { psychiatric patients in the geographic area } \\
\text { where you practice? }(N=45)\end{array}$} \\
\hline Yes & 6 & 13 \\
\hline No & 39 & 87 \\
\hline \multicolumn{3}{|c|}{$\begin{array}{l}\text { Are you aware of any laboratories that provide } \\
\text { genetic testing in the geographic area } \\
\text { where you practice? }(N=45)\end{array}$} \\
\hline Yes & 14 & 31 \\
\hline No & 31 & 69 \\
\hline \multicolumn{3}{|c|}{$\begin{array}{l}\text { To your knowledge, is genetic counseling } \\
\text { covered by most forms of insurance in the } \\
\text { geographic area where you practice? } \\
(\mathrm{N}=45)\end{array}$} \\
\hline Yes & 1 & 2 \\
\hline No & 7 & 16 \\
\hline Do not know & 37 & 82 \\
\hline \multicolumn{3}{|c|}{$\begin{array}{l}\text { To your knowledge, is genetic testing covered } \\
\text { by most forms of insurance in the } \\
\text { geographic area where you practice? } \\
(N=45)\end{array}$} \\
\hline Yes & 1 & 2 \\
\hline No & 7 & 16 \\
\hline Do not know & 37 & 82 \\
\hline
\end{tabular}

${ }^{a}$ Variations in reported $N$ are due to missing or incomplete responses.

in genetics in the past 5 years stated that they were competent to offer and interpret genetic tests, but none of those without recent training felt competent to do so $(P<0.02$, Fisher exact test). Almost $80 \%$ of respondents had not ordered any genetic tests during the past 5 years (Table 6). Tests for Fragile X syndrome were ordered by more respondents with than without recent training in genetics ( $28 \%$ vs. $4 \%, P<0.07$, Fisher exact test). Ordering tests for Alzheimer disease, neurofibromatosis, or some other condition was reported only by respondents with recent training in genetics.

Thirty-one percent of respondents were aware of laboratories providing genetic testing in the area in which they practiced (Table 6). More respondents who had genetics training within the previous 5 years were aware of laboratories that provide testing compared with those who had not had such recent training (56\% vs. $15 \%, P<0.01$, Fisher exact test). More than three-fourths of respondents (82\%) stated that they did not know whether most forms of insurance in their geographic area covered genetic testing and genetic counseling.

\section{DISCUSSION}

To our knowledge, this preliminary study is the first to poll a random national sample of US psychiatrists on these issues, and it is the first to report an association between recent training in genetics and a greater experience in providing genetic services. The response rate for this study is similar to that achieved by other psychiatrist surveys on genetics, most of which have been limited by the use of sampling methods without the potential to yield generalizable data. Although our sample was small, it was sufficient to demonstrate that psychiatrists had strong beliefs in the influence of genetics on mental illness and positive attitudes toward providing genetic services and to support our hypothesis that psychiatrists with recent genetics training would be more prepared to offer services. These findings will be discussed in detail below.

\section{Perceptions of the influence of genetics on illnesses, traits, and abilities}

As an indirect method of assessing respondents' genetics knowledge, we asked psychiatrists for their perceptions of the influence of genetics on conditions and traits. These survey items have ecological validity, because most respondents stated that they routinely talked to patients and families about the influence of genetics on mental illness. All 27 conditions and traits listed in the survey instrument are believed to have some genetic basis, though in many cases, heritability estimates are broad ranges that may be challenging to interpret in a meaningful way for individual patients. ${ }^{28}$

It is important not to over interpret our respondents' answers to these survey items, given the limitations of this type of assessment. However, a few general observations can be made. First, every psychiatrist in our sample believed that genetics played some role in the development of most of the psychiatric disorders listed. Furthermore, none of the psychiatrists gave answers that were consistently dismissive of the influence of genetic factors in psychiatric or medical diseases or in human traits, behaviors, and abilities - that is, no one chose "no influence" of genetics for all items within any of the three categories. Second, participants discriminated between individual disor- 
ders, behaviors, and traits when estimating the influence of genetics, which is in accord with scientific evidence that heritability is not uniform within or between these categories.

It is also notable that the accuracy of our respondents' answers varied across conditions. More than $90 \%$ correctly identified Huntington disease, a Mendelian disorder with autosomal dominant inheritance, as a condition for which genetics has a strong influence. No psychiatrist selected "weak influence" or "no influence" on this question. On the other hand, for the question concerning autism-a complex inheritance disease whose published heritability estimates are $>90 \%{ }^{29}$ nearly half of the respondents chose weak influence or no influence. This latter result is similar to the finding of the Finn et al. ${ }^{21}$ survey of attendees at a CME psychopharmacology course in Boston, in which psychiatrists gave a median estimate of $10 \%$ when asked to estimate the heritability of autism.

Finally, it is of potential interest that our respondents' overall ratings of genetic influences on mental disorders was significantly greater than their ratings for medical disorders, and that both groups of illnesses were rated as being significantly more influenced by genetics than traits and abilities. Again, these data should not be over interpreted, because the conditions and traits selected for the questionnaire were not selected to be representative of the three general categories. Nevertheless, this observation may reflect psychiatrists' views about the relative heritability of various types of complex inheritance disorders and traits, which merits testing in a future study and comparison with other clinical and lay samples.

\section{Positive attitudes toward providing genetic services}

The psychiatrists in our sample demonstrated a positive attitude toward the incorporation of genetic services in the clinical practice of psychiatry. Almost all stated that providing genetic information to psychiatric patients and their families was appropriate to their clinical role, and most stated that psychiatrists were the most appropriate professional to provide genetic counseling to psychiatric patients. These findings were generally consistent with the results of the Finn et al. ${ }^{21}$ study, in which $83 \%$ of the psychiatrists surveyed believed that providing genetic information to patients and families was important to their clinical role.

Interestingly, a much greater percentage of our sample felt competent $(70 \%)$ and adequately trained $(60 \%)$ to provide genetic information than was reported in the Finn et al. study (23\% and $15 \%$, respectively). This disparity may be the result of differing ascertainment methods, as our participants were recruited from a random sampling of US physicians, and the prior work's respondents were ascertained through attendance at a CME pharmacology course. Compared with US psychiatrists as a whole, clinicians attending the continuing education course may have been more likely to perceive themselves as somewhat deficient in competency or training, at least at that time and in that setting.

Another possibility is that the difference in results is due to an ordering effect of the items on the two questionnaires. In our questionnaire, items about self-perceived competency and adequacy of genetics training appeared before questions asking respondents to estimate heritability, which were the only items that assessed genetics knowledge in any fashion. In the Finn survey, the relevant questions appeared at the end of the questionnaire, after several test-style psychiatric genetics questions and general genetics questions (CT Finn, Personal communication, 2008). Nearly $85 \%$ of respondents to the Finn survey answered fewer than half of the test-style questions correctly. Respondents' difficulty with these items may have affected their judgment of personal competency and adequacy of genetics training. Indeed, the authors reported a significant association between self-assessed competence and higher scores on the survey's measures of genetics knowledge.

It is important to note that psychiatrists' perceptions of their competence to offer genetic services are not necessarily an accurate reflection of their actual competence. Indeed, our finding that $35 \%$ of respondents had no genetics training within the previous 20 years calls into question the ability to provide precise and detailed information to patients and families about the heritability of illness. Furthermore, the current survey literature on this topic has clearly identified deficits in psychiatrists' genetic knowledge. ${ }^{19-22}$

Psychiatrists' actual genetics knowledge and competence is not simple to measure, however. Most psychiatrists' genetic surveys have used voluntary, self-administered written questionnaires, a type of instrument that most respondents complete very rapidly, expending as little time as possible on each question. ${ }^{30}$ Busy physicians may not have the time or motivation to carefully work through genetics problems presented in a voluntary survey and instead may skip such items, answer "don't know," or choose the first response that seems reasonable. Psychiatrists' genetics knowledge may be more accurately measured by analyzing responses to genetics questions on tests that psychiatrists are motivated to perform well upon-for example, the psychiatry resident-in-training exam or the written examination for certification by the American Board of Psychiatry and Neurology. To our knowledge, no such data have been published.

\section{Clinical experience with genetic counseling and testing}

Many psychiatrists in this study reported some experience in providing genetic counseling for their patients. Most respondents routinely took family histories of psychiatric illness and talked to at least some patients about the role of genetics in their illness. However, few psychiatrists had made referrals to genetic counselors during the previous year, were aware of any genetic counselors in the area providing services to patients with psychiatric illness, or knew whether genetic counseling was covered by insurance. These results may be due to a lack of psychiatric genetic counseling services rather than, or in addition to, a lack of knowledge of existing resources.

When asked about clinical scenarios in which they might refer to a genetic counselor or counsel patients themselves, the psychiatrists demonstrated an ability to identify certain presentations suggestive of an underlying Mendelian disorder (a psychiatric patient with multiple congenital anomalies or 
mental retardation) and a desire to refer such patients to genetic counselors. Overall, the psychiatrists' responses to this group of items were generally consistent with recommendations for primary care referral to genetic counseling that have been established by the American College of Medical Genetics. ${ }^{31}$

It is also interesting to note that most psychiatrists reported that counseling patients about genetic influences on their illness made some patients more distressed about having a mental illness and some patients less distressed, in about equal numbers. This observation is pertinent to a growing debate over how the "geneticization" of mental illness is likely to affect the social stigmatization of psychiatric disorders and patients' self-esteem. Some experts and patients believe that a genetic or other biological explanation for mental illness demonstrates that these diseases are as "real" as physical illnesses and that the patients should therefore not be blamed for their suffering. ${ }^{32}$ An alternative view is that characterizing mental illnesses as genetic disorders saddles patients with an additional, stigmatizing label—that of being genetically defective, even "mutant." 33 To our knowledge, the current study is the first to provide empirical data on psychiatrists' perceptions of the psychological impact of genetic information on their patients. Our finding suggests that both sides of the debate may be correct: some individuals will find comfort in knowing that genetics is partially responsible for their mental disease, and others will be distressed by the same information. These results must be interpreted cautiously, however, as patients' emotional responses to information about the heritability of their disease could be influenced by many factors, such as the clinician's sensitivity, relationship with the patient, and factual understanding of psychiatric genetics.

Regarding genetic testing, the psychiatrists in our sample reported very limited clinical experience, and nearly all said they did not feel competent to offer genetic tests for psychiatric illnesses and interpret the results. These results were not unexpected, given the paucity of genetic tests currently available for psychiatric conditions, ${ }^{16,34}$ and they suggest that our sample was not biased in favor of clinicians who provide an unusual amount of genetic services. This finding is also noteworthy because the lack of experience and self-assessed competence represents a potential barrier to the future provision of services.

\section{Association between recent genetics training and clinical experience}

Our hypothesis that more recent genetics training would be associated with greater preparedness was supported in part by the finding of an association between training and clinical genetics experience. We did not find differences in attitudes toward genetic medicine in the attitude items described here. Nor did we find any meaningful pattern of differences in psychiatrists' assessment of the influence of genetics on various conditions.

The discovery of an association between recent genetics training and clinical experience is noteworthy, because it suggests that targeting genetic education interventions at psychiatrists may translate into changes in practice. We found, for example, that the recently genetics-trained respondents were more likely than other psychiatrists to say that they routinely took family health histories and discussed the genetic component of psychiatric illness with their patients. The size of these differences was moderate ( $100 \%$ vs. $77 \%$ and $89 \%$ vs. $64 \%$ ), though not statistically significant. Significant differences were seen in the items concerning genetic testing. None of the respondents without recent genetics training stated that they were competent to offer and interpret genetic tests, in contrast to $24 \%$ of the recently trained psychiatrists. The recently trained psychiatrists were also significantly more likely to be aware of laboratories that provided genetic testing and were more likely to have ordered tests for Fragile X disorder. All of the respondents who reported having ordered tests for Alzheimer disease, neurofibromatosis, or "other" were in the recently trained group. The association between greater provision of genetic services and recent genetics training persisted even after controlling for other potentially confounding factors, such as board certification status, gender, age, and treating children and adolescents.

\section{Strengths and limitations}

The strengths of this study include the use of a probability sampling method to assess the readiness of psychiatrists to provide services in a clinical area that is integral to future psychiatric practice. ${ }^{16,17,34}$ Limitations of this study include the use of a new instrument that relies on self-report data; the lack of a comparison group such as other health professionals, patients, or families; and the small sample size. The sample size limited our ability to perform subgroup analysis, though it was sufficient to detect some suggestive and significant differences associated with recent genetics training. Because our survey relied on self-report data, we have no independent corroboration of respondents' answers regarding their genetics training and their experience in providing clinical services.

In addition, although the response rate was acceptable and there were no differences between respondents and nonrespondents on all measurable demographic items, we cannot exclude the possibility of nonresponse bias because of differences in genetic knowledge and/or interest among respondents and nonrespondents. It should be noted that we employed several strategies to minimize this form of bias, including the exclusion of test-style genetics questions from the survey on the grounds that they might reduce the response rate in general and might particularly deter those with less interest or knowledge in genetics. Cover letters mailed with the surveys explained that genetics knowledge was not a prerequisite for participating in the survey, and that we were seeking the opinions of all psychiatrists, including those with little or no background or interest in genetics. Nevertheless, we were unable to contact nonrespondents to assess differences in attitudes and experiences between those who participated in the survey and those who did not. If nonresponse bias is a significant factor, we would expect it to skew our results toward more positive attitudes 
regarding genetics and/or toward a greater degree of clinical experience in providing genetics counseling and testing.

\section{Directions for future research}

Future studies with larger samples and including comparison groups such as genetic counselors, medical geneticists, and other clinicians are warranted, as are prospective studies of the results of educational interventions designed to help psychiatrists prepare for the genome era. The results of the current study provide some guidance about the content of future educational interventions. It seems that psychiatrists do not need to be persuaded that genetics is important to learn or that mental disorders are heritable, but they do need practical information about providing and referring to genetic services such as genetic counseling. When and if more genetic tests become clinically available, psychiatrists will need information about ordering those tests and interpreting their results.

Many other aspects of psychiatrists' "genetic readiness" remain to be explored empirically. For example, how ready are psychiatrists to answer patients' questions about emerging applications of genetics that may come to their attention through media reports, such as direct-to-consumer genetic testing or "personalized medicine"? How ready are psychiatrists to provide empirical risk information to patients and families? Individualized estimates of recurrence risk for complex inheritance psychiatric disorders, though challenging to compile, ${ }^{35-37}$ may be highly valuable to consumers. ${ }^{17}$

Other promising areas for future research include detailed assessments of the adequacy of the numbers of psychiatrists, clinical geneticists, and genetic counselors to meet the projected future need for clinical psychiatric genetic services, and assessments of the genetics educational needs and preferences of child/adolescent psychiatrists and other psychiatric subspecialists. Finally, the ethical aspects of psychiatric genetics have generated a great deal of discussion, ${ }^{7,26,38-42}$ but relatively little is known about how psychiatrists view this subject and about their educational needs regarding ethical and legal duties.

\section{CONCLUSION}

This survey of a probability sample of US psychiatrists' readiness to offer genetics services has identified areas of strength among our respondents (positive attitudes about providing these services, belief in the heritability of mental illness) and potential targets for educational interventions (general genetics training, information about testing and counseling resources). Physicians' predisposition to pursue lifelong learning has been conceptualized to comprise several factors, including the motivation to learn and the ability to recognize one's own educational needs..$^{43}$ Most psychiatrists in our sample reported that understanding genetics was important to their professional role, and they recognized and acknowledged limitations in their current level of competence, particularly in regard to genetic testing. Furthermore, those who had more recent genetics training were more likely to provide the genetic services that are currently available. Thus, although these findings sug- gest that US psychiatrists require additional genetics education to be prepared for the genome era, it also provides reason to be optimistic that such efforts may be both welcome and effective.

\section{ACKNOWLEDGMENTS}

Dr. Hoop gratefully acknowledges support from the $\mathrm{Na}$ tional Institute of Health in the form of a National Research Service Award (T32 MH200065).

The authors also thank Edwin H. Cook, Jr, MD; Elliot Gershon, MD; Caleb Alexander, MD; Cheryl A. Roe, MA; and Ann Tennier, BS, for their assistance in this work.

\section{References}

1. Farmer A, Owen MJ. Genomics: the next psychiatric revolution? Br J Psychiatry 1996;169:135-138.

2. McGuffin P, Southwick L. Fifty years of the double helix and its impact on psychiatry. Aust N Z J Psychiatry 2003;37:657-661.

3. Rutter M. Nature, nurture, and development: from evangelism through science toward policy and practice. Child Dev 2002;73:1-21.

4. Hoop JG, Cook J, Edwin H, Dinwiddie SH, et al. Neurogenetics, behavior, and neurodegenerative disorders. In: Sharpe NF, Carter RF, editors. Genetic testing: care, consent, and liability. Hoboken, NJ: Wiley-Liss, 2006:223-237.

5. Prathikanti S, Weinberger DR. Psychiatric genetics - the new era: genetic research and some clinical implications. Br Med Bull 2005;73-74:107-122.

6. Zuchner S, Roberts ST, Speer MC, Beckham JC. Update on psychiatric genetics. Genet Med 2007;9:332-340.

7. DeLisi LE, Bertisch H. A preliminary comparison of the hopes of researchers, clinicians, and families for the future ethical use of genetic findings on schizophrenia. Am J Med Genet B Neuropsychiatr Genet 2006;141:110-115.

8. Jones I, Scourfield J, McCandless F, Craddock N. Attitudes towards future testing for bipolar disorder susceptibility genes: a preliminary investigation. J Affect Disord 2002;71:189-193.

9. Meiser B, Mitchell PB, McGirr H, Van Herten M, et al. Implications of genetic risk information in families with a high density of bipolar disorder: an exploratory study. Soc Sci Med 2005;60:109-118.

10. Milner KK, Han T, Petty EM. Support for the availability of prenatal testing for neurological and psychiatric conditions in the psychiatric community. Genet Test 1999;3:279-286.

11. Schulz PM, Schulz SC, Dibble E, Targum SD, et al. Patient and family attitudes about schizophrenia: implications for genetic counseling. Schizophr Bull 1982;8:504-513.

12. Smith LB, Sapers B, Reus VI, Freimer NB. Attitudes towards bipolar disorder and predictive genetic testing among patients and providers. J Med Genet 1996;33:544-549.

13. Trippitelli CL, Jamison KR, Folstein MF, Bartko JJ, et al. Pilot study on patients' and spouses' attitudes toward potential genetic testing for bipolar disorder. Am J Psychiatry 1998;155:899-904.

14. Austin JC, Smith GN, Honer WG. The genomic era and perceptions of psychotic disorders: genetic risk estimation, associations with reproductive decisions and views about predictive testing. Am J Med Genet B Neuropsychiatr Genet 2006;141:926-928.

15. Finn CT, Smoller JW. Genetic counseling in psychiatry. Harv Rev Psychiatry 2006; 14:109-121.

16. Finn CT. Increasing genetic education for psychiatric residents. Harv Rev Psychiatry 2007;15:30-33.

17. Austin JC, Honer WG. The genomic era and serious mental illness: a potentia application for psychiatric genetic counseling. Psychiatr Serv 2007;58:254-261.

18. Collins FS. Preparing health professionals for the genetic revolution. JAMA 1997; 278:1285-1286.

19. Suther S, Goodson P. Barriers to the provision of genetic services by primary care physicians: a systematic review of the literature. Genet Med 2003;5:70-76.

20. Hofman KJ, Tambor ES, Chase GA, Geller G, et al. Physicians' knowledge of genetics and genetic tests. Acad Med 1993;68:625-632.

21. Finn CT, Wilcox MA, Korf BR, Blacker D, et al. Psychiatric genetics: a survey of psychiatrists' knowledge, opinions, and practice patterns. J Clin Psychiatry 2005;66: 821-830.

22. Chase GA, Geller G, Havstad SL, Holtzman NA, et al. Physicians' propensity to offer genetic testing for Alzheimer's disease: results from a survey. Genet Med 2002;4:297-303.

23. Verma R, Corley DA. How should we select health professionals for studies? Outcomes Manag 2003;7:129-133.

24. Description of AMA physician masterfile data elements. Available at: https:// profiles.ama-assn.org/amaprofiles/info/pdf/mfile_elements.pdf. Accessed January 10,2008 
25. How the data elements on the AMA physician masterfile are collected, maintained, and verified. Available at: https://profiles.ama-assn.org/amaprofiles/ info/pdf/primarysource.pdf. Accessed January 10, 2008.

26. Hoop JG, Roberts LW, Green Hammond KA, Cox NJ. Psychiatrists' attitudes toward genetic testing and patient safeguards: a preliminary study. Genetic Testing. In press.

27. Freedman AN, Wideroff L, Olson L, Davis W, et al. US physicians' attitudes toward genetic testing for cancer susceptibility. Am J Med Genet A 2003;120:63-71.

28. Feinberg SS. Psychiatric genetics. J Clin Psychiatry 2006;67:324.

29. Folstein SE, Rosen-Sheidley B. Genetics of autism: complex aetiology for a heterogeneous disorder. Nat Rev Genet 2001;2:943-955.

30. Dillman DA. Mail and internet surveys: the tailored design method, 2nd ed. New York: John Wiley \& Sons, 2000.

31. Pletcher BA, Toriello HV, Noblin SJ, Seaver LH, et al. Indications for genetic referral: a guide for healthcare providers. Genet Med 2007;9:385-389.

32. Corrigan PW, Watson AC. At issue: stop the stigma: call mental illness a brain disease. Schizophr Bull 2004;30:477-479.

33. Phelan JC. Genetic bases of mental illness—a cure for stigma? Trends Neurosci 2002; 25:430-431.

34. Guttmacher AE, Porteous ME, McInerney JD. Educating health-care professionals about genetics and genomics. Nat Rev Genet 2007;8:151-157.
35. Austin JC, Palmer CG, Rosen-Sheidley B, Veach PM, et al. Psychiatric disorders in clinical genetics II: individualizing recurrence risks. J Genet Couns 2007;17:18-29.

36. Austin JC, Peay HL. Applications and limitations of empiric data in provision of recurrence risks for schizophrenia: a practical review for healthcare professionals providing clinical psychiatric genetics consultations. Clin Genet 2006;70:177-187.

37. Peay HL, Veach PM, Palmer CG, Rosen-Sheidley B, et al. Psychiatric disorders in clinical genetics. I: addressing family histories of psychiatric illness. J Genet Couns 2007;17:6-17.

38. Appelbaum PS. Ethical issues in psychiatric genetics. J Psychiatr Pract 2004;10:343-351

39. Clayton EW. Ethical, legal, and social implications of genomic medicine. N Engl J Med 2003;349:562-569.

40. Dinwiddie SH, Hoop J, Gershon ES. Ethical issues in the use of genetic information. Int Rev Psychiatry 2004;16:320-328.

41. Farmer A, McGuffin P. Ethics and psychiatric genetics. In: Bloch S, Chodoff P, Green SA, editors. Psychiatric ethics, 3rd ed. Oxford, New York: Oxford University Press, 1999:479-494.

42. Nuffield Council on Bioethics. Genetics and human behavior: the ethical context Available at: http://www.nuffieldbioethics.org/go/ourwork/behaviouralgenetics/ publication_311.html. Accessed January 4, 2008.

43. Hojat M, Veloski J, Nasca TJ, Erdmann JB, et al. Assessing physicians' orientation toward lifelong learning. J Gen Intern Med 2006;21:931-936. 